\title{
Social Esteem and Participation in Contentious Politics: A Field Experiment at an LGBT Pride Rally
}

\author{
Gwyneth H. McClendon Harvard University
}

\begin{abstract}
What motivates individuals to participate in contentious, political forms of collective action? In this article, I consider the possibility that the promise of social esteem from an ingroup can act as a powerful selective incentive for individuals to participate in contentious politics. I conducted a field experiment-the first to my knowledge to take place in the context of a political march, rally, or social-identity event-to isolate this esteem mechanism from others. Using measures of intent to attend, actual attendance, and reported attendance at a gay and lesbian pride event in New Jersey, I find evidence that the promise of social esteem boosts all three measures of participation. The article offers new theoretical and practical implications for the study of participation in nonvoting forms of collective action.
\end{abstract}

$\mathrm{F}$ rom recent protests in the Middle East (Anderson 2011) to participation in the U.S. civil rights movement (Chong 1991), from demonstrations against the Soviet Union (Beissinger 2002) to mass protests in various parts of sub-Saharan Africa (Bratton and van de Walle 1992), understanding the occurrence of "contentious politics"1 — of marches, protests, rallies, and social movements-has long been of interest to political scientists. Many researchers focus on the structural conditions and dynamic processes that lead to the occurrence of such events (Beissinger 2002; Bratton and van de Walle 1992; Kielbowicz and Scherer 1986; Opp 1998; Tarrow 1998). Yet implicit or explicit in these macrotheories are questions about the factors that motivate individuals to take part in contentious forms of collective action.

When, where, and why does an ordinary citizen decide to take part in contentious politics? Many scholars looking at political participation from an individual-level perspective, particularly those with a rational-choice focus, have been puzzled by the occurrence of any kind of collective action. They contend that each individual should abstain because she stands to benefit from not participating-from "free riding" off of others (DiPasquale and Glaeser 1996; Muller 1980; Olson 1965).

One plausible solution that has not yet been tested in a nonvoting collective action setting is that the opportunity to rise in the opinion of social peers is a powerful selective incentive. ${ }^{2}$ A long line of social psychological and neurological research demonstrates that people desire esteem from ingroup members (Cuddy et al. 2009; Fiske 2010; Immordino-Yang et al. 2009). Experimental studies of voter turnout and of charitable giving have found that knowing political actions will be made public to one's community increases materially costly behavior (DellaVigna, List, and Malmendier 2012; Funk 2010; Gerber, Green, and Larimer 2008; Panagopoulos 2010; Sinclair 2012; Soetevent 2005). There is reason to suppose

Gwyneth H. McClendon is Assistant Professor of Government and Social Studies, Harvard University, 1737 Cambridge St., CGIS K207, Cambridge, MA 02138 (gwyneth_mcclendon@harvard.edu).

Replication files and anonymized data will be made available through AJPS's Dataverse. The experiment was approved by the Princeton University Institutional Review Board before the study was conducted. Special thanks to the staff of the cooperating LGBT organization and to the Mamdouha S. Bobst Center for Peace and Justice for funding the conduct of the experiment. Thank you to the MacMillan Center at Yale University for support during write-up and revisions. Previous versions of this article were presented at Princeton University, Yale University, New York University, and the 2012 Annual Meeting of the Midwest Political Science Association. Thank you to Kevin Arceneaux, Graeme Blair, Carles Boix, Elizabeth Carlson, Kevin Collins, Ana De La O, Eric Dickson, Donald Green, Scott Hartman, Leonie Huddy, Sigrun Kahl, Robert Keohane, Evan Lieberman, Peter Loewen, Daniel Oppenheimer, Victoria Shineman, Susan Stokes, Tariq Thachil, Rick Wilson, and three anonymous reviewers for comments on earlier drafts. All shortcomings are mine.

${ }^{1}$ Contentious politics are "episodic, public, collective interaction[s] among makers of claims and their objects when (a) at least one government is a claimant, an object of claims or a party to the claims and (b) the claims would, if realized, affect the interests of at least one of the claimants" (McAdam, Tarrow, and Tilly 2001, 5).

${ }^{2}$ Olson (1965) and Chong (1991) suggest this possibility but do not test it.

American Journal of Political Science, Vol. 58, No. 2, April 2014, Pp. 279-290

(C) 2013, Midwest Political Science Association

DOI: 10.1111/ajps.12076 
that the desire to look good in front of other members of an ingroup might also motivate people to participate in the domain of contentious politics.

Observational studies of contentious politics have highlighted a strong association between social ties and participation (e.g., Kuran 1991; Lohmann 1993; Opp and Kittell 2010; Schussman and Soule 2005), but we do not know if this link is causal. Furthermore, such a link could operate through several different mechanisms: the provision of information, the mobilization of grievances, or the promise of social esteem. Whether one or any of these mechanisms is at work has never been rigorously tested.

In this article, I leverage random assignment in a realworld setting to test whether the promise of ingroup esteem induces participation in a collective, social-identity event. To my knowledge, this experiment is the first to examine actual participation in a contentious political event. Each of 3,651 potential participants in a rally and march promoting gay rights was randomly assigned to one of three conditions. Two of those conditions meant that the subject was invited to participate in the event with an explicit promise of esteem from other members of the lesbian, gay, bisexual, and transgender (LGBT) community. The third condition meant that the subject was invited with information only about the timing, purpose, and location of the event.

The specific event posed hurdles for the main hypothesis. The cooperating organization coordinates events through email, an impersonal mode of communication that has been found in the past to have no effect on other forms of participation (see Nickerson 2007 on voter turnout; cf. Malhotra, Michelson, and Valenzuela 2012). Furthermore, there are still enough costs in the United States to being publicly identified as having attended an LGBT event that even the leaders of the organization hosting the event predicted that the treatments might actually discourage attendance. Nevertheless, using three measures of participation (intent to participate, actual participation, and reported participation), I found that the promise of ingroup esteem induced higher rates of participation than simply informing individuals of the purpose, timing, and location of the event.

The study thus makes several theoretical and empirical contributions. First, it provides evidence that the link between social ties and participation in contentious politics is causal at least when operating through the mechanism of social esteem. It also makes an argument for why individuals might view the promise of social esteem for participating in contentious politics as a credible promise. Second, it extends findings about extrinsic rewards as well as field experimental methods from studies of voter turnout and donations to a new domain. In doing so, it takes the unusual step of measuring participation in three different ways (intended, actual, and reported) and offers guidance as to how to study participation in contentious settings despite the logistical challenges. Third, it questions previous findings that electronic communication cannot be effective in mobilizing political behavior.

The article proceeds as follows. Next, I discuss the possible link between social esteem and participation in contentious politics, given extant findings in political, social psychological, and sociological research. I then describe the experimental design and present the main results. I conclude with a discussion of external validity and practical implications for future field experiments on contentious politics.

\section{Ingroup Esteem and Rally Participation}

Olson (1965) famously argued that rational, selfinterested individuals participate in collective action only when they can gain excludable benefits from doing so. Such excludable benefits might be tangible or intangible. Materially, individuals might be paid to participate (Brown 2003) or believe that participating provides them with needed physical security (Scacco 2012). Psychologically, participants might be frustrated with their living conditions and see participation simply as an opportunity to vent aggression (Keen 1988) or to have fun (Banfield 1968), or individuals might be intrinsically motivated to stand up for a cause they believe in (Inman and Andrews 2011; Klandermans 2002).

Selective incentives might also be social. Indeed, one common argument in the literature on participation in contentious politics is that social ties are necessary to bring individuals into the fray (Goodwin 1997; Kuran 1991; Lohmann 1993; Opp and Kittell 2010; Pfaff 1996; Schussman and Soule 2005). People have been observed to join the action if they have some prior social connection to other joiners (McAdam 1986; Opp and Kittell 2010), and they seem more likely to participate if they have been asked to do so (Klandermans and Oegema 1987). These social "pull" factors appear to persist both in the presence and in the absence of material and psychological incentives. ${ }^{3}$

Of course, a host of unobservable factors could drive social ties to other participants and the decision to participate, so we do not know if these associations are causal.

\footnotetext{
${ }^{3}$ See Kitts (2000) for a review.
} 
Furthermore, there could be at least three mechanisms that link prior social ties to participation. First, when embedded in a social network, an individual has access to accurate information about when, where, and under what conditions the event will take place (Chwe 1999; Kuran 1991; Lohman 1993). These bits of information can facilitate her participation and perhaps reassure her that the costs will not be overwhelming (an informational mechanism). Second, there could be a grievance mechanism whereby social ties help to build a sense of shared identity and purpose (Fireman and Gamson 1979; Kitts 2000, 241; Klandermans 2002). Finally, via a social esteem mechanism, social ties might spur people to participate because individuals value their social standing within groups (Chong 1991; della Porta 1988; Klandermans 1984; Sinclair 2012). Individuals may be told that joining in will win them the esteem of other group members. On the flip side of the same coin, they may fear the social shaming that will result if they abstain (Panagopoulos 2010). This third mechanism is rooted in a concern for within-group status. It depends on the promise that others will both observe and reward participation.

The latter mechanism has been shown to influence voter turnout. When told that whether they vote or abstain will be made public to other members of their households or communities, individuals are more likely to turn up at the polls (e.g., Gerber, Green, and Larimer 2008; Panagopoulos 2010; Sinclair 2012). Indeed, reducing the material costs of voting does not necessarily boost turnout if the act of voting simultaneously becomes more private (Funk 2010); the deleterious effect of less observable voting on turnout has been found to be more dramatic in smaller communities where the desire for social esteem and incentives to avoid shame are likely to be more acute (Funk 2010). These results are consistent with a model in which individuals derive utility from the high opinion of other members of their social-identity groups even when earning such a high opinion is materially costly (Akerlof and Kranton 2000; Ali and Lin 2013; Benabou and Tirole 2006; DellaVigna, List, and Malmendier 2012).

That participation in contentious collective action could credibly earn an individual social esteem from an ingroup is also consistent with research in social psychology on the antecedents of admiration. According to this research, admiration is a positive emotion directed at individuals who are perceived as both competent and warm (Fiske 2010; Immordino-Yang et al. 2009). Competence involves perceived skill and efficaciousness. Warmth involves perceived friendliness and cooperativeness. Participation in collective action conveys warmth when an individual is acting on behalf of a clearly defined social group. By choosing to show up on behalf of a group, individuals demonstrate visible support for the interests of others in that group particularly because participants could have reaped all of the benefits of a successful collective endeavor while staying at home.

Participation in contentious collective action also conveys competence because it necessitates that individuals take action. Participants have to arrange to arrive on site; they take on tasks to facilitate the event. They do not stay at home, free riding off of the efforts of others. Although nonparticipants may be at work or engaged in other activities apart from the event, they are not easily identified as such and may be perceived as ineffective. Indeed, that opponents of social movements often engage in efforts to characterize participants in contentious politics as "lazy" and "incapable" suggests that the perception of participants as competent is powerful enough to warrant countering. ${ }^{4}$

At least on these grounds there are a priori reasons to suppose that social esteem can be credibly promised in the context of a political protest, rally, or pride event. All else equal, promising ingroup social esteem should then increase participation. The study thus tests the following hypothesis.

H1: Individuals who receive an explicit promise of admiration from ingroup members for participating in contentious politics on behalf of the group should on average be more likely to participate than those who learn simply about the goals and logistics of the event.

\section{Experimental Design}

Subjects in the experiment were members of an LGBT advocacy and support organization in New Jersey (hereinafter "the cooperating organization"). The cooperating organization coordinated a political event that included a rally and march intended to celebrate the LGBT community, to recognize the repeal of "Don't Ask Don't Tell," and to demonstrate support for marriage equality in the state. The event took place in October 2011 and provided an instance of collective action on behalf of a well-defined social-identity group.

While there are many examples throughout the world of events conducted on behalf of social-identity groups, I

\footnotetext{
${ }^{4}$ Listen, for instance, to Rush Limbaugh's radio comments about the Occupy Wall Street protesters on October 6, 2011, on "The Rush Limbaugh Show."
} 
examined this one for the following ethical and theoretical reasons. First, while the event took place in a physically safe environment, it still involved contentious issues. In particular, marriage of same-sex couples was not legal in New Jersey, and, despite changes in the neighboring state of New York, at the time of this writing New Jersey did not recognize same-sex marriages performed elsewhere. The governor has been quite vocally opposed to legalization and vetoed a marriage-equality bill in February 2012. ${ }^{5}$ Disappointed with the open opposition of the governor to marriage equality, the cooperating organization designed the event to demonstrate support.

Second, the nature of the group and the mode of communication provided hurdles for the main hypothesis. Subjects were invited through an email listserv, a very impersonal form of communication. One might expect that the promise of social esteem would not be convincing when communicated electronically (Nickerson 2007) and among individuals who, though committed at least nominally to a common social-identity group, do not necessarily have deep relationships with each other (Sinclair 2012). The LGBT community is also a social-identity group whose members often cannot be identified by outward appearance. Many members, even in New Jersey, still do not want to be publicly "outed," particularly as part of an explicitly political event. As a result, they might actually be less willing to participate in an LGBT event if told that their participation will be observed (even if celebrated) by others. Indeed, the staff of the cooperating organization predicted that the treatments in this study would depress participation within this particular group, even if the treatments might boost participation in other settings. That I find significant and large treatment effects here might increase confidence in the generalizability of a social-esteem-based explanation for contentious political participation.

The cooperating organization's listserv had 4,066 email address entries before the experiment took place. Of these, 415 were dropped prior to randomization either because they were duplicates of other email addresses on the list or because they were listed next to business or organization, rather than individual, names. This left 3,651 individual email addresses across which treatments were randomized. Each email address was assigned to one of three conditions. (The online appendix contains a CONSORT diagram.)

The cooperating organization sent out the email invitations a week before the event, using an online listserv-

\footnotetext{
5"I am not a fan of same-sex marriage. ... I wouldn't sign a bill like the one that was in New York." Chris Christie interview on Meet the Press, June 26, 2011, quoted in Molly Peterson, "Christie Says He's 'Not a Fan' of Gay Marriage," Bloomberg News.
}

management program, Vertical Response. Because Vertical Response keeps track of any email addresses to which mail is undeliverable and because the cooperating organization regularly sends out emails, ${ }^{6}$ the list of email addresses remains one of active email addresses, and very few, if any, emails bounce in any given batch sent out. In the case of this experiment, the system deemed only four emails undeliverable. The four corresponding email addresses were dropped from subsequent analysis.

Vertical Response also keeps track of recipients who click on an icon within the email in order to "display images below." When this action is observed, I can be fairly certain that a human being opened the email and attempted to read it closely. In other words, not only was contact made with these subjects (the email did not bounce back), but they also tried to engage with the messages sent to them. I refer to this behavior below as "closely reading the email." The measure is probably not perfect. Other subjects may have read the emails closely but happen to have email clients that automatically display images within emails or display emails in text format only. Thus, in the analyses below, I always first present intent-to-treat effect estimates. Subsequently, I test for the effect of having closely read the social-esteem promising emails on participation.

\section{Treatments}

Three types of email invitations were sent out. The text of the emails differed. In one condition (the informationonly condition), individuals were told the goals of the event and told when and where they should go to participate. The second email text (the newsletter condition) contained the same content as the first. Subjects in this condition, however, were also told that participants are worthy of admiration and that their names would be listed in the monthly newsletter if they attended so that their attendance could be "celebrated" by other members of the organization. This condition gave subjects the promise that participation would be observed and symbolically rewarded by ingroup members.

This second condition is similar to treatments used in studies of social rewards for voting, specifically to the social "pride" condition in Panagopoulos (2010) in which only individuals who do the socially esteemed thing (voting or, in this case, participating in the rally) are publicly

\footnotetext{
${ }^{6}$ Individuals on this listserv receive emails from the organization on average about once a week during the summer and fall months, about once every month or two months the rest of the year.
} 
listed. ${ }^{7}$ Panagopoulos (2010) finds that this type of treatment has a positive but weaker effect on voting than listing only those individuals who do not do the socially valued thing. By using this form of the treatment, I am thus both explicitly looking at the effect of promising social esteem (rather than disesteem) and also creating a tougher test for the ingroup status hypothesis.

In order to test whether any treatment effect is due to the publicizing of valued behavior and the promise of social esteem in general rather than to the specific use of a newsletter or of a list of names, a third version of the email (the Facebook condition) was also sent out. This version mimicked the second, but rather than promising that participants' names would be circulated in a list in the newsletter, the Facebook condition instead invited participants to post photos from the event to the group's Facebook page so that other group members could "like" the photos. (There is no Facebook option to "dislike" posts.)

\section{Email Text $^{8}$}

From: [cooperating organization]

Subject: Rally for Marriage Equality on October [date]

Join us on October [date] and support marriage equality. We have the greatest admiration for anyone who takes the time to support LGBT causes, [so we will be listing the names of people who attend in our monthly newsletter, to be shared with and celebrated by all of our supporters. $]^{*} /[$ so we invite you to post your photos from the event on our Facebook page so that friends can show their support for attendees by "Liking" the posts. $]^{* *}$

When: [date]

Where: [location]

At the entrance... you will get FREE raffle tickets to win an $\mathrm{iPad} 2$ when you present the following code: [ ].

An Evite will follow immediately. We need to know how many people to expect, so please RSVP.

Note: Italicized words were not included in emails to information-only subjects.

*This clause in brackets as well as the preceding italicized phrase were included in emails to subjects in the newsletter condition.

${ }^{7}$ Other studies (e.g., Gerber, Green, and Larimer 2008) have publicized both voters and nonvoters.

${ }^{8}$ Steps have been taken to anonymize the email text while still accurately conveying the content of the treatments.
**This clause in brackets as well as the phrase "We have the greatest admiration..." were included in emails to subjects in the Facebook condition.

One might be concerned, given the slightly longer length of the emails in the newsletter and Facebook conditions or given that they both explicitly call recipients potential supporters of LGBT causes, that these emails primed some other motivation (e.g., the importance of the event or cause). Through a postexperiment survey, I explore other possible mechanisms. The evidence suggests that the perceived promise of esteem for participating, rather than many other possible motivations, drove the results.

Individuals in all three conditions were also told that, by presenting a code (provided in the email and different for each experimental condition) at the entrance to the site, they could obtain free tickets for a raffle to win an iPad2. The cooperating organization had previously conducted raffles as part of its public-advocacy and social events, so this detail provided a mechanism for keeping a record of attendees but was unlikely to introduce novelty effects. We could both count the number of individuals who showed each code and match the attendees' names, which they wrote on the raffle ticket stubs, to the cooperating organization's listserv. The email information about the code also ensured that the subjects assigned to the information-only condition had an explicit incentive to check in. One might otherwise have worried that subjects assigned to the esteem conditions made sure to have their presence noticed while those in the informationonly condition attended the event but less conspicuously. If that were the case, any difference in actual participation across the three conditions could be due to measurement error.

It turned out that the raffle codes also reduced email forwarding. Because of the concern, for instance, that information-only subjects might be inadvertently treated with esteem emails by receiving forwarded messages from friends, all social media sharing options within the emails were disabled. ${ }^{9}$ Recipients could still, however, forward through their own email clients, so in the postexperiment survey, respondents were asked to recall if they had received forwarded emails from friends and/or other organizations about the march and rally. Only four respondents reported having received forwarded messages sent by the cooperating organization that differed in content from the one they had originally received. Four might seem oddly low. Yet, in an open-ended survey question

${ }^{9}$ In general, however, this kind of behavior would have undermined the treatment effects I find. 
about forwarding, respondents reported not having forwarded the emails because of the raffle code. Some who planned on attending reported they thought that the code was an individual one or that they did not want to share the lottery code and thereby depress their chances of winning the iPad2; subjects who did not plan on attending reported that they thought the lottery code was an individualized lottery code and therefore could be used only by them.

\section{Measures of Participation}

Individual participation in contentious politics is rarely systematically and publicly documented. As a result, previous studies have looked at self-reports of intent to participate (Inman and Andrews 2011; Klandermans 2002) or of reported past participation (e.g., Bratton et al. 2005; Mueller 2013; Scacco 2012). Few, if any, of these studies examine actual participation.

In this study, I first gathered a behavioral measure of intentions to participate. In the email invitations, subjects were asked to RSVP. Specifically, subjects were directed to an Evite on which they could RSVP "yes" or "no." I had set up three websites, one for each condition. Each repeated the exact text from the respective email message. Individuals with email addresses not in a given condition were blocked from RSVPing on that site.

Second, as mentioned above, participation at the event was measured using raffle tickets. Attendees presented the code from their email invitation to volunteers at the event. ${ }^{10}$ The code each individual presented was written on the back of the ticket stubs along with her name and email address, so that she could be contacted were she to win. Each participant had her hand stamped so she could not present a code twice.

Third, an online survey was sent to all listserv members a week after the event. All respondents viewed identical surveys but arrived at the survey questions through a link corresponding to their assigned treatment condition. On the survey, respondents were asked if they attended the event. Survey respondents were also asked to explain their decisions to attend (or not to attend) the event; to indicate whether they received forwarded emails; to answer demographic, political and group attachment questions; and to give the cooperating organization feedback about the event.

\footnotetext{
${ }^{10}$ Volunteers did not themselves receive the emails or know which
} code corresponded to which condition.

\section{Ethical Considerations}

As in many large-scale field experiments, I did not ask subjects for their consent, except in the context of the postexperiment survey, and I did not debrief subjects. Debriefing was not used because the experiment included no deception and because the subjects' identities and personal information were always kept by the cooperating organization, an organization to whose listserv subjects had voluntarily subscribed. All of the information provided to potential attendees was accurate. All subjects had voluntarily registered their email addresses with the cooperating organization in order to receive information about events like this one. Subjects can unsubscribe from the listserv at any time. Omitting the details of the study should not have posed any additional risk to the subjects and ensured against Hawthorne effects. Subjects' personal information was stored only in the cooperating organization's Vertical Response account or collected by volunteers at the event. Before I transferred information about participation to personal computers, I replaced names and email addresses with subject numbers. Replication data and the email text described in this article are anonymized. Evite websites with personal email addresses were disabled after data analysis. The ticket stubs with personal identifying information were destroyed once all the data were collected. This protocol was designed to protect subjects' confidentiality and adhere to privacy statements on the cooperating organization's website.

\section{Results}

I first consider two of the outcome measures: intended participation (coded 1 for a "yes" RSVP on the Evite and 0 otherwise) and actual participation (coded 1 when a subject picked up a ticket at the entrance to the event and 0 otherwise). Because of randomization, consistent estimates of the effects of assignment to different email messages, or the ITT effects, can be calculated as the mean outcome for a treatment message (either newsletter or Facebook) minus the average outcome for the information-only group.

Table 1 shows differences in mean rates of participation between the newsletter treatment group and the information-only group, then between the Facebook treatment group and the information-only group, and then the pooled results. For both the newsletter and Facebook treatments, assignment to that condition led to a positive and statistically significant increase in 


\section{TABLE 1 Differences in Rates of Participation}

\begin{tabular}{|c|c|c|}
\hline & $\begin{array}{c}\text { Intent to } \\
\text { Participate }\end{array}$ & $\begin{array}{c}\text { Actual } \\
\text { Participation }\end{array}$ \\
\hline \multicolumn{3}{|l|}{ Effect of newsletter treatment } \\
\hline \multirow[t]{2}{*}{ Newsletter } & $6.08 \%$ & $3.04 \%$ \\
\hline & $\mathrm{N}=1217$ & $\mathrm{~N}=1217$ \\
\hline \multirow[t]{2}{*}{ Information-only } & $3.53 \%$ & $1.72 \%$ \\
\hline & $\mathrm{N}=1217$ & $\mathrm{~N}=1217$ \\
\hline Difference & 2.55 & 1.32 \\
\hline (S.E.) & $(0.867)$ & $(0.618)$ \\
\hline p-value (two-sided Welch) & 0.003 & 0.034 \\
\hline \multicolumn{3}{|l|}{ Effect of Facebook treatment } \\
\hline \multirow[t]{2}{*}{ Facebook } & $5.93 \%$ & $2.96 \%$ \\
\hline & $\mathrm{N}=1213$ & $\mathrm{~N}=1213$ \\
\hline \multirow[t]{2}{*}{ Information-only } & $3.53 \%$ & $1.72 \%$ \\
\hline & $\mathrm{N}=1217$ & $\mathrm{~N}=1217$ \\
\hline Difference & 2.40 & 1.24 \\
\hline (S.E.) & $(0.861)$ & $(0.614)$ \\
\hline p-value (two-sided Welch) & 0.005 & 0.043 \\
\hline \multicolumn{3}{|l|}{ Pooled results } \\
\hline \multirow[t]{2}{*}{ Newsletter and Facebook } & $6.01 \%$ & $3.00 \%$ \\
\hline & $\mathrm{N}=2430$ & $\mathrm{~N}=2430$ \\
\hline \multirow[t]{2}{*}{ Information-only } & $3.53 \%$ & $1.72 \%$ \\
\hline & $\mathrm{N}=1217$ & $\mathrm{~N}=1217$ \\
\hline Difference & 2.48 & 1.28 \\
\hline (S.E.) & $(0.720)$ & $(0.509)$ \\
\hline p-value (two-sided Welch) & 0.001 & 0.012 \\
\hline
\end{tabular}

participation relative to the information-only group. ${ }^{11}$ The newsletter email produced a 2.55 percentage point increase in intended participation and a 1.32 percentage point increase in actual participation relative to the information-only email. Similarly, the Facebook email induced a 2.40 percentage point increase in intended participation and a 1.24 percentage point increase in actual participation. $^{12}$

While these numbers might at first seem small, they are substantively large. Base actual participation in the

\footnotetext{
${ }^{11}$ Although $\mathrm{H} 1$ specified an increase in participation in the treatment groups relative to the control, I used a two-sided t-test because the cooperating organization hypothesized a decrease. Based on results from Shapiro Wilk tests, there may be slight deviations from a normal distribution in intent to participate and actual participation, but it is a large sample. Statistically significant differences are also found using Mann-Whitney tests.

${ }^{12}$ Difference-in-difference estimation does not reveal a statistically significant difference between the size of the effect from assignment to the newsletter treatment (relative to the information-only condition) and the size of the effect from assignment to the Facebook treatment (relative to the information-only condition).
}

TABLE 2 Effect of Closely Reading Esteem Emails on Participation-IV Estimates

\begin{tabular}{lcc}
\hline & $\begin{array}{c}\text { DV = Intent to } \\
\text { Participate }\end{array}$ & $\begin{array}{c}\text { DV = Actual } \\
\text { Participation }\end{array}$ \\
\hline Closely reading an & 0.315 & 0.163 \\
esteem email & $(0.090)$ & $(0.063)$ \\
Constant & 0.035 & 0.017 \\
& $(0.005)$ & $(0.004)$ \\
Number of & 3647 & 3647 \\
$\quad$ observations & & 0.108 \\
R-squared & 0.079 & \\
\hline
\end{tabular}

2SLS. Instrumented: Closely read an esteem email. Instrument: Assigned to one of the esteem emails (either newsletter or Facebook). Bootstrapped standard errors in parentheses.

information-only condition was only $1.72 \%$, or 21 people. The effect of assignment to the newsletter treatment therefore represented a $76 \%$ increase in actual participation relative to the information-only condition, resulting in 37 people participating from that treatment group. The effect of assignment to the Facebook treatment likewise represented a $71 \%$ increase in actual participation (to 36 people from that group), relative to the information-only condition. These are both meaningful increases in participation for organizers.

Table 7 in the online appendix presents regression estimates from models that include the three baseline covariates available before the experiment: gender, distance of residential address from the event site, and number of years affiliated with the cooperating organization. ${ }^{13}$ Including these controls has little effect on the ITT estimates.

To estimate the effect of closely reading the treatment emails, as opposed to simply being assigned to receive them, I use an instrumental variable (IV) approach where random assignment to one of the two esteem emails is an instrument for reading the social-esteem-promising emails, as measured by Vertical Response's tracking of who clicked "display images below" within the email messages. The first stage of the IV estimation confirmed that assignment to the newsletter/Facebook treatments is not a weak instrument for closely reading one of the socialesteem-promising emails, with an F-test statistic of 104. Table 2 shows the IV estimates of the effects of closely reading an esteem email on intent to participate and on

${ }^{13}$ The first two of these had to be inferred from email addresses and IP addresses used when subjects registered with the listserv. Future studies might endeavor to collect pre-experiment covariates through a pre-experiment survey. OLS regression results with controls are reported in the appendix, but the results are robust to using logit instead. 
TABLE 3 Differences in Rates of Reported Participation

\begin{tabular}{lccccc}
\hline & $61.00 \%$ & & $59.79 \%$ & Newsletter and & $60.40 \%$ \\
Newsletter & $\mathrm{N}=100$ & Facebook & $\mathrm{N}=97$ & Facebook & $\mathrm{N}=197$ \\
Information-only & $45.54 \%$ & - & - & - & - \\
& $\mathrm{N}=101$ & & - & & - \\
\hline Difference & $\mathbf{1 5 . 4 6}$ & Difference & $\mathbf{1 4 . 2 5}$ & Difference & $\mathbf{1 4 . 8 6}$ \\
$\quad$ S.E.) & $\mathbf{( 6 . 9 9 )}$ & (S.E.) & $\mathbf{( 7 . 0 6 )}$ & (S.E.) & $\mathbf{( 6 . 0 8 )}$ \\
p-value (two-sided Welch) & $\mathbf{0 . 0 2 8}$ & p-value (two-sided Welch) & $\mathbf{0 . 0 4 5}$ & p-value (two-sided Welch) & $\mathbf{0 . 0 1 5}$ \\
\hline
\end{tabular}

actual participation, which are much larger than the corresponding ITT estimates. The effect of closely reading an esteem treatment email on actual participation, for instance, is more than 12 times greater than the corresponding ITT effect (16.3 percentage points versus 1.3 percentage points). Table 8 in the appendix shows these effects separately for the newsletter and Facebook treatments, which, on actual participation, are 12 and 13 times greater than the corresponding ITT effects from Table 1.

Next, I consider reported participation (coded 1 if an affirmative answer was given when asked on the postexperiment survey about attendance at the event). I have measures of this outcome only for individuals who responded to the postexperiment survey (298 people). This is not a representative sample of the overall subject pool. Indeed, the rate of reported participation within this group is higher than the rate of actual or intended participation was in the larger subject pool. Nevertheless, I cannot reject the null hypothesis that survey response rates were the same across treatment conditions. One hundred people from the newsletter treatment, 97 people from the Facebook treatment, and 101 people from the information-only condition responded, and the Pearson chi-square statistic from a $2 \times 3$ table is 0.08 (p-value $=$ 0.96). Table 9 in the online appendix presents these results. ${ }^{14}$ I therefore consider whether assignment to the newsletter and Facebook conditions boosted reported participation within this subgroup of the subject pool.

Table 3 shows differences in rates of reported participation across conditions among survey respondents. The estimated differences here are also statistically significant and substantively large. Assignment to the newsletter treatment is estimated to boost the rate of reported participation by 15.46 percentage points relative to assignment to the information-only condition. Assignment to

\footnotetext{
${ }^{14}$ Individual characteristics reported on the survey (gender, age, race, partisanship, residential location, education, employment status, and so on), which arguably would not have changed posttreatment, are also balanced across treatment groups among survey respondents. See Table 6 in the online appendix.
}

the Facebook treatment is estimated to boost the rate of reported participation by 14.25 percentage points. The pooled effect on reported participation from assignment to the newsletter or Facebook condition is 14.86 percentage points. These estimates remain statistically significant when individual covariates (female, previous attendance at a coordinating organization pride event, voted in 2010, age, unemployed, democrat) measured in the survey are accounted for. See Table 11 in the online appendix.

The survey measure of reported participation is useful for probing another possibility: if subjects in the information-only condition were more likely than other subjects to attend but not to pick up their raffle tickets, the results for actual participation in Tables 1 and 2 could be driven by bias in measurement of that outcome. To check, I created a dummy variable "no pickup" with a value of 1 for individuals who reported on the postexperiment survey that they attended the event but who were not recorded as having actually attended. This dummy variable was coded 0 for all other individuals who responded to the survey.

I cannot reject the null hypothesis that "no pickup" rates were the same across conditions. If anything, more people assigned to the two esteem conditions (38 out of 100 in the newsletter condition, 36 out of 97 in the Facebook condition) did not pick up their tickets at the event but reported that they attended in the survey, compared to those assigned to the information-only condition (30 out of 101). The Pearson chi-square statistic for this $2 \times 3$ table is $2.08(\mathrm{p}=0.35) .{ }^{15}$ These numbers clearly indicate that there was some slippage between measures of reported participation and of actual participation in this study. I return to this point in the concluding discussion. But while the correlation between the two measures was not perfect overall, I cannot reject the null that any mismatch did not differ systematically across treatment conditions.

\footnotetext{
${ }^{15}$ The corresponding p-value from a Fisher exact test is 0.34 .
} 


\section{Explanations of Participation}

One might be concerned that the newsletter and Facebook treatments primed some motivation other than the desire for esteem. Perhaps, for instance, because they were slightly longer emails than the information-only email, the treatment emails primed the importance of the event or triggered subjects' intrinsic concern for LGBT causes. Perhaps by mentioning other members and social networking sites, they reminded subjects of the social nature of the event and made them think it would be more fun or that they would meet people.

If the treatment emails had an effect on participation because they primed esteem, however, I would expect to observe evidence of this pattern in follow-up questions on the postexperiment survey. Survey respondents were asked why they chose to participate or not. For those who reported participating, the question was as follows:

For which of the following reasons, if any, did you attend on October []? (Choose all that apply.)

- I went to promote a cause I care about;

- I went for camaraderie, to meet people or to hang out with friends;

- I went to have fun;

- I went because I had time and/or it was easy for me to get there;

- I went because people in my community would think highly of people who attend;

- I went because I am interested in a leadership position with [the cooperating organization];

- I went because it was an important event for [the cooperating organization].

The fifth option listed here indicates that participation promised esteem ("I went because people in my community would think highly of people who attend"). If the treatments primed esteem, one would expect mean selection of this option to be higher among attendees assigned to the newsletter or Facebook conditions than among attendees assigned to the information-only condition. And, indeed, as can be seen in Table 4, while $67 \%$ of respondents who had been assigned to one of the esteem conditions and who reported attending the event chose that option, only $22 \%$ of respondents assigned to the information-only condition who reported attending chose this option. A one-sided t-test of this difference in means yields a p-value less than 0.001. By contrast, the frequency of reporting other motivations did not differ across the social-esteem-promising and information-only conditions among those who attended.

Likewise, for those who reported not attending, the question was as follows:
For which of the following reasons, if any, did you not attend on October []? (Choose all that apply.)

- I did not think the cause was that important;

- I did not know anyone else who was going;

- I did not think it would be fun;

- I did not have time and/or it was too difficult for me to get there;

- I did not feel that my participation would be admired by people in my community;

- I am not interested in a leadership position with [the cooperating organization];

- I did not think it was an important event for [the cooperating organization].

Here, the fifth option indicates that participation does not promise social esteem. If the treatments primed the promise of social esteem, I expect that, on average, individuals assigned to the esteem conditions would choose this fifth option to explain their lack of participation less frequently than individuals assigned to the informationonly condition would.

And, indeed, as can be seen in Table 4, none of the respondents who had been assigned to one of the esteem conditions and who did not attend chose the fifth option. By contrast, $30 \%$ of respondents assigned to the information-only condition who did not attend chose that option. A one-sided t-test of this difference in means yields a p-value less than 0.001. Meanwhile, the frequency of choosing the other answers did not differ across treatment conditions.

While not definitive, these numbers suggest that, on average, the difference between those assigned to the esteem conditions and those assigned to the informationonly condition among both attendees and nonattendees was their perception that participation at the event would win them social esteem and not other elements of their reasoning about the event.

\section{Discussion}

To my knowledge, this study is the first field experiment to examine participation in a rally, march, or other contentious political event. Through this experiment, I found that subjects responded positively and dramatically to the promise that their participation would be observed and admired by others. Indeed, I found substantively and statistically significant effects of this promise even when using a relatively impersonal mode of invitation (email); when treating an LGBT group, whose members might perceive "outing" costs to having their participation publicly recorded; and when using a treatment that 


\section{TABLE 4 Differences in Mean Rates of Choosing a Reason for Participation Behavior}

\begin{tabular}{|c|c|c|c|}
\hline & Esteem & Information-Only & Difference (SE) \\
\hline \multicolumn{4}{|l|}{ Attendees } \\
\hline I went to promote a cause I care about & 0.521 & 0.543 & $0.022(0.087)$ \\
\hline I went for camaraderie, to meet people... & 0.520 & 0.630 & $0.109(0.085)$ \\
\hline I went to have fun & 0.294 & 0.369 & $0.075(0.083)$ \\
\hline I went because I had time... & 0.286 & 0.261 & $-0.025(0.078)$ \\
\hline I went because ... highly of people who attend & 0.672 & 0.217 & $-0.455(0.075)$ \\
\hline I went because ... a leadership position... & 0.521 & 0.500 & $-0.021(0.088)$ \\
\hline I went because it was an important event... & 0.336 & 0.369 & $0.033(0.084)$ \\
\hline \multicolumn{4}{|l|}{ Nonattendees } \\
\hline I did not think the cause was that important & 0.013 & 0.055 & $0.042(0.033)$ \\
\hline I did not know anyone else who was going & 0.205 & 0.218 & $0.013(0.073)$ \\
\hline I did not think it would be fun & 0.962 & 0.964 & $0.002(0.034)$ \\
\hline I did not have time... & 0.462 & 0.509 & $0.047(0.089)$ \\
\hline I did not feel that ... would be admired... & 0.000 & 0.309 & $0.309(0.063)$ \\
\hline I am not interested in a leadership position... & 0.808 & 0.800 & $-0.008(0.071)$ \\
\hline I did not think it was an important event... & 0.642 & 0.710 & $0.068(0.083)$ \\
\hline
\end{tabular}

emphasized the admiration rewards of participating rather than the shaming costs of not participating.

Other studies have found evidence that social rewards mobilize participation when it comes to voting and donations. This experiment provides evidence that the influence of social rewards extends to other domains of political behavior. And, while a status-based selective incentive has been suggested in previous scholarship on contentious politics to explain the robust correlation between social ties and participation, this study isolated the promise of ingroup esteem from the information- and grievancebased mechanisms that could have also explained that same correlation.

Future research could extend the findings of this study in multiple ways. Since there is a rich observational scholarship on protests, demonstrations, and rallies, there are myriad theories, and not just the social esteem one tested here, that could be further tested with the advantages of random assignment in the context of real-world contentious political events. Related research has suggested, for instance, that priming individuals with a sense of injustice, of their own efficacy, and of their linked fate with social-identity groups could also motivate participation in contentious politics (e.g., Van Zomeren, Postmes, and Spears 2008). This study tested specifically for the effects of promising social esteem relative to providing information about the event, but the basic framework of the experiment could be extended to testing these other theories.
In contrast to elections, contentious political events tend to be more spontaneous, and individual participation is not automatically and publicly recorded, so this study offers ideas to researchers looking to overcome these and other obstacles. Working with an advocacy organization meant that I was aware several weeks in advance that the event would take place. I took advantage of the fact that the cooperating organization regularly conducts raffles at their political and social events. Any such previously used mechanism (a sign-in sheet, the handout of wrist bands, the taking of group pictures) could be exploited to systematically record individual participation without introducing novelty effects. Using recording devices other than a raffle would also test whether the treatment effects found here are specific to people who like to participate in lotteries. In addition, one could imagine training volunteers (who know participants but not which conditions they have been assigned to) to keep journals of individual participation. While this study measured participation only in a binary way, journal observations would also allow researchers to measure intensity of participation (how long participants stay at the event, the kinds of activities they engage in while there).

This study also took the unusual step of collecting three different measures of participation (intended, actual, and reported). Yet while the promise of social esteem boosted rates of participation no matter how participation was measured, the three measures were 
not perfectly correlated with each other. Inconsistencies across measures occurred primarily in two ways. About $4.7 \%$ of the subjects (170 subjects) either indicated they intended to come but were not observed attending and did not report attending or indicated they would not come and then showed up and reported showing up. One might call these the flaky subjects; they changed their minds after RSVPing yes or no. Another 2.9\% (104) reported attending the event but were not observed doing so based on the raffle-ticket measure. These subjects may have indeed attended but not been interested enough in the event to pick up tickets, or they may have lied on the survey. I could not reject the null hypotheses that these "no pickup" subjects were distributed evenly across treatment conditions in this study, but the discrepancies suggest that any one measure of participation does not tell the full story. Future studies might endeavor to gather pre-event, during, and post-event measures of participation in order to probe further the correspondence among the three and to understand better which individuals exhibit consistent behavior and which do not.

This study also raises questions about external validity that are ripe for future research. Since this experiment is the first such field experiment on contentious politics participation, only further experimentation can test whether treatment effects of these same sizes and statistical significance would be found in other settings. For instance, would we expect treatment effects of this size in a more dangerous context? It is possible that social esteem promises would, in fact, be more powerful in risky, costly settings (Chong 1991). Such settings offer an opportunity to make a greater sacrifice on behalf of one's group and therefore win an even greater degree of admiration, but we can assess whether this is the case only with further tests. One might also ask whether there are other social-identity groups that are more or less sensitive to symbolic, status-based promises than the group considered here, and whether the promise of ingroup esteem would produce the same effects if it were delivered by peers rather than by leaders of an organization. In general, future research could explore whether the effects found here vary with the riskiness of the environment, the contentiousness of the issue, the types of individuals and groups targeted, and with how messages meant to encourage participation are delivered.

\section{References}

Akerlof, George, and Rachel Kranton. 2000. "Economics and Identity.” Quarterly Journal of Economics 115: 715-53.
Ali, S. Nageeb, and Charles Lin. 2013. "Why People Vote: Ethical Motivations and Social Incentives." American Economic Journal 5(2): 73-98.

Anderson, Lisa. 2011. "Demystifying the Arab Spring." Foreign Affairs 90: 2.

Banfield, Edward. 1968. "Rioting Mainly for Fun and Profit." In The Metropolitan Enigma: Inquiries into the Nature and Dimensions of America's Urban Crisis, ed. James Wilson. Cambridge, MA: Harvard University Press, 283-308.

Beissinger, Mark. 2002. Nationalist Mobilization and the Collapse of the Soviet State. New York: Cambridge University Press.

Benabou, Roland, and Jean Tirole. 2006. "Incentives and Prosocial Behavior.” American Economic Review 96(5): 1653-78.

Bratton, Michael, Robert Mattes, and Emmanual GyimahBoadi. 2005. Public Opinion, Democracy, and Market Reform in Africa. Cambridge: Cambridge University Press.

Bratton, Michael, and Nicholas van de Walle. 1992. "Popular Protest and Political Reform in Africa." Comparative Politics 24(4): 419-42.

Brown, Stephen. 2003. "Quiet Diplomacy and Recurring Ethnic Clashes in Kenya." In From Promise to Practice: Conflict, ed. Chandra Sriram and Karin Wermester. Boulder, CO: Lynne Rienner, 69-100.

Chong, Dennis. 1991. Collective Action and the Civil Rights Movement. Chicago: University of Chicago Press.

Chwe, Michael Suk-Young. 1999. "Structure and Strategy in Collective Action." American Journal of Sociology 105: 12856.

Cuddy, Ann, et al. 2009. "Is the Stereotype Content Model Culture-Bound? A Cross-Cultural Comparison Reveals Systematic Similarities and Differences." British Journal of Social Psychology 48: 1-33.

della Porta, Donatella. 1988. "Recruitment Processes in Clandestine Political Organizations: Italian Left-Wing Terrorism." In From Structure to Action, ed. Bert Klandermans, Hanspeter Kriesi, and Sidney Tarrow. Greenwich, CT: JAI Press, 155-69.

DellaVigna, Stefano, John A. List, and Ulrike Malmendier. 2012. "Testing for Altruism and Social Pressure in Charitable Giving." Quarterly Journal of Economics 127(1): 1-56.

DiPasquale, Denise, and Edward Glaser. 1998. "The Los Angeles Riot and the Economics of Urban Unrest." Journal of Urban Economics 43(1): 52-78.

Fiske, Susan. 2010. Envy Up, Scorn Down: How Status Divides Us. New York: Russell Sage Foundation.

Funk, Patricia. 2010. "Social Incentives and Voter Turnout: Evidence from the Swiss Mail Ballot System." Journal of the European Economic Association 8(5): 1077-1103.

Gerber, Alan S., Donald P. Green, and Christopher W. Larimer. 2008. "Social Pressure and Voter Turnout: Evidence from a Large-Scale Field Experiment." American Political Science Review 102(1): 33-48.

Goodwin, Jeff. 1997. "The Libidinal Constitution of a HighRisk Social Movement: Affectual Ties and Solidarity in the Huk Rebellion." American Sociological Review 62: 53-69.

Immordino-Yang, Mary Helen, Andrea McColl, Hanna Damasio, and Antonio Damasio. 2009. "Neural Correlates of 
Admiration and Compassion." Proceedings of the National Academy of Sciences 106(19): 8021-26.

Inman, Kris, and Josephine Andrews. 2011. "Corruption and Political Participation in Africa: Evidence from Survey and Experimental Research." Working paper, University of California, Davis.

Keen, David. 1998. The Economic Functions of Violence in Civil Wars. Oxford: Oxford University Press.

Kielbowicz, Richard B., and Clifford Scherer. 1986. "The Role of the Press in the Dynamics of Social Movements." Research in Social Movements, Conflicts and Change: A Research Annual 9: 71-96.

Kitts, James. 2000. "Mobilizing Black Boxes: Social Networks and Participation in Social Movement Organization." Mobilization 5: 241-57.

Klandermans, Bert. 2002. "How Group Identification Helps to Overcome the Dilemma of Collective Action." American Behavioral Scientist 45(5): 887-900.

Klandermans, Bert, and Dirk Oegema. 1987. "Potentials, Networks, Motivations and Barriers: Steps toward Participation in Social Movements." American Sociological Review 52: 519-31.

Kuran, Tim. 1991. "Now Out of Never: The Element of Surprise in the East European Revolution of 1989." World Politics 44: $7-48$.

Lohmann, Susanne. 1993. "A Signaling Model of Informative and Manipulative Political Action." American Political Science Review 87: 319-33.

Malhotra, Neil, Melissa Michelson, and Ali Adam Valenzuela. 2012. "Research Note: Emails from Official Sources Can Increase Turnout." Quarterly Journal of Political Science 7(3): 321-32.

McAdam, Doug. 1986. "Recruitment to High-Risk Activism: The Case of Freedom Summer." American Journal of Sociology 92: 64-90.

McAdam, Doug, Sidney Tarrow, and Charles Tilly. 2001. Dynamics of Contention. Cambridge: Cambridge University Press.

Mueller, Lisa. 2013. "Democratic Revolutionaries or Pocketbook Protestors? The Roots of the 2009-2010 Uprisings in Niger." African Affairs 112(448): 398-448.

Muller, Edward. 1980. "The Psychology of Political Protest and Violence." In Handbook of Political Conflict Theory and Research, ed. Ted Gurr. New York: Free Press, 69-99.

Nickerson, David. 2007. "Does Email Boost Voting Turnout?" Quarterly Journal of Political Science 2: 369-79.
Olson, Mancur. 1965. The Logic of Collective Action: Public Goods and the Theory of Groups. Cambridge, MA: Harvard University Press.

Opp, Karl-Dieter. 1998. "Social Networks and Protest Norms." In Social Norms, ed. Michael Hechter. New York: Russell Sage Foundation, 234-73.

Opp, Karl-Dieter, and Bernhard Kittel. 2010. “The Dynamics of Political Protest: Feedback Effects and Interdependence in the Explanation of Protest Participation." European Sociological Review 26(1): 97-109.

Panagopoulos, Costas. 2010. "Affect, Social Pressure and Prosocial Motivation: Field Experimental Evidence of the Mobilizing Effects of Pride, Shame and Publicizing Voting Behavior." Political Behavior 32: 369-86.

Pfaff, Steven. 1996. "Collective Identity and Informal Groups in Revolutionary Mobilization: East Germany in 1989." Social Forces 75(1): 91-118.

Scacco, Alexandra. 2012. Anatomy of a Riot: Participation in Ethnic Violence in Nigeria. Book manuscript, New York University.

Schussman, Alan, and Sarah Soule. 2005. "Process and Protest: Accounting for Individual Protest Participation." Social Forces 84(2): 1083-1107.

Sinclair, Betsy. 2012. The Social Citizen. Chicago: University of Chicago Press.

Soetevent, Adriaan. 2005. "Anonymity in Giving in a Natural Context: A Field Experiment in 30 Churches." Journal of Public Economics 89(11): 2301-23.

Tarrow, Sidney. 1998. Power in Movement: Social Movements and Contentious Politics. New York: Cambridge University Press.

Van Zomeren, Martijn, Tom Postmes, and Russell Spears. 2008. "Toward an Integrative Social Identity Model of Collective Action: Quantitative Research Synthesis of Three SocioPsychological Perspectives." Psychological Bulletin 134(4): 503-35.

\section{Supporting Information}

Additional Supporting Information may be found in the online version of this article at the publisher's website:

Summary statistics and robustness tests of the main results. 